\title{
Innovative Disruption: The Case of the Diamond Industry
}

\author{
Charles A. Rarick \\ Purdue University Northwest \\ Arifin Angriawan \\ Purdue University Northwest
}

\begin{abstract}
For many decades the diamond industry remained stable with De Beers firmly in control of supply and generating demand. The diamond cartel has since ended as outside suppliers of natural stones entered the market but the potential for the greatest change comes from outside the traditional industry and the technology brought to the marketplace. Diamonds no longer need to be mined but can now be produced in a high-tech manufacturing facility, creating not an artificial diamond, but one that is chemically identical to natural diamonds. This innovative disruption in the diamond industry has gained momentum and threatens the entire structure of the industry.
\end{abstract}

\section{INTRODUCTION}

The diamond industry is perhaps on the verge of massive disruption with the introduction of manmade diamonds. Natural diamonds are produced the earth's mantle when carbon is exposed to extreme pressure. Diamonds make their way to the earth's surface through a volcanic eruption and can be found above ground, but more frequently mined where a kimberlite pipe is discovered. It takes the earth over a billion years to produce a diamond but now real diamonds can be produced in a laboratory in a small fraction of the time and be sold at prices significantly lower than natural diamonds. This disruptive innovative technology may forever change the diamond industry.

\section{THE ROLE OF DE BEERS}

For many years the diamond industry was controlled by De Beers. The company was responsible for exploration, mining, and selling most of the diamonds in the world. De Beers was started by an Englishman named Cecil Rhodes. Rhodes was in the business of supplying water pumps to South African gold mines, but with the discovery of diamonds in that country Rhodes began buying up land believed to hold diamonds. Some of this land was owned by two brothers named de Beers. Cecil Rhodes began the world's first diamond syndicate, but the cartel's long running success can be attributed to Ernest Oppenheimer. Oppenheimer was the Chairman of De Beers who began buying diamonds on the open market during the Great Depression; a time when diamond prices were falling. Oppenheimer, with the help of an ad agency named N.W. Ayer \& Sons created the lasting tag line - a diamond is forever. Oppenheimer was also responsible for the success of pairing diamonds with love. Through effective advertising he was able to create the practice of giving a loved one a diamond ring as a sign of devotion, 
commitment, and love. In the late 1930 s only $10 \%$ of American brides received a diamond ring as a sign of engagement but that number rapidly grew to around 80\% (The Economist, 2017) as a diamond engagement ring became standard practice thanks to De Beers' demand management strategy. On the pricing side De Beers established the "two months" salary standard as the appropriate budget for a diamond engagement ring purchase. De Beers became the buyer of last resort for the diamond market and the firm stockpiled diamonds in its London vaults. The company would buy diamonds from anyone in the world without regard to its source. The rough diamonds would be taken to London where they were evaluated and sorted. Ten times a year De Beers offered its diamonds to select buyers at non-negotiated prices. Since De Beers controlled most of the diamond producing mines in South Africa, Botswana, and Namibia it had significant control over the world's diamond supply. By selectively managing supply the company was able to keep prices high.

\section{PROBLEMS FOR DE BEERS}

For De Beers this control started to shrink with increasing diamond production coming out of Russia and other countries. De Beers, now part of Anglo American once controlled $90 \%$ of the world's diamonds. Now the company controls approximately a third of global supply (Ewingmay, 2015). While still a major player in the diamond industry, De Beers is no longer able to exercise the control it once enjoyed. Major players outside the De Beers cartel, such as Russia's ALROSA are adding additional supply to the market. In recent years diamond prices have been volatile and showing a downward trend (Figure 1). IDEX, the diamond price index shows a current downward trend in diamond prices, however, a report by Bain \& Company (2016) indicates that while prices have fallen and profit margins reduced, diamond mining output is expected to begin to fall as it appears that the major diamond fields may have already been found. Consumers seeking natural stone may be forced to pay higher prices or switch to man-made diamonds.

\section{FIGURE 1} IDEX

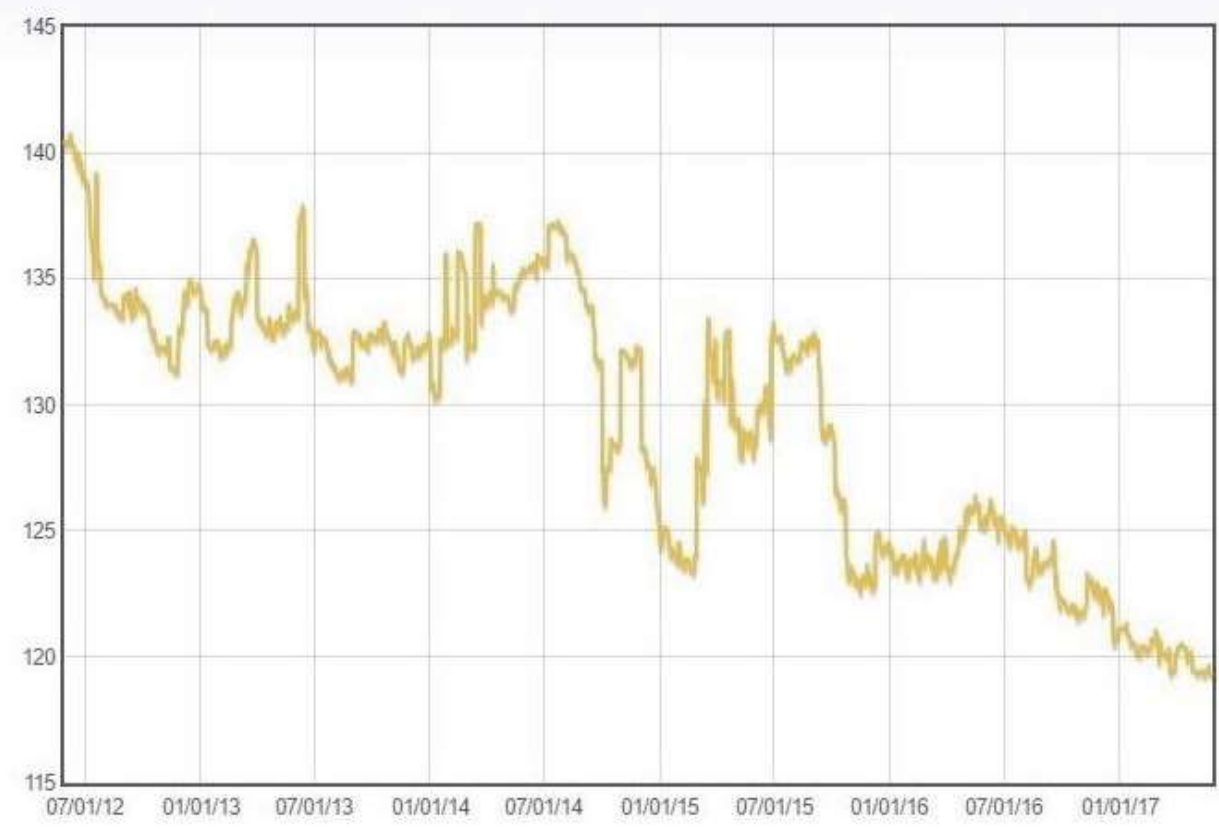

Source: www.idexonline.com 
In addition to reduced market control, De Beers and the entire industry faced a significant challenge when diamonds became the source of funding for revolutions and rebellions. For many years diamonds were evaluated based on what was called the Four Cs: carat, clarity, color, and cut. After production of the 2006 film titled, Blood Diamonds, an additional C was sometimes added to the list for evaluationconflict free. The film highlighted the problems of diamonds being used to fund rebellion and civil war in certain African countries. Sierra Leone, Angola, Congo, as well as other countries were being accused of using diamond sales to finance their civil war activities. In response to these concerns and with the help of many NGOs, in May 2000 representatives of diamond producing countries in Africa met in Kimberley, South Africa and drew up an agreement to certify that diamonds exported from member countries were conflict-free (Bieri, 2010). The Kimberley Process Certification Scheme (KPSC) requires its 54 participating countries to establish procedures to ensure that its diamond exports are not funding rebellion, and to package the diamonds in tamper-resistant shipping containers (Kimberley Process, 2017). Member countries are not allowed to trade diamonds with non-member countries. Any member country not in compliance with the agreement will be banned from trading with other countries and the diamonds may be considered tainted by conflict and human rights abuses. While the conflicts in Angola, Sierra Leone, and Congo have mostly come to an end, other concerns about diamond sourcing remain. The continuing threat of rebellion in other countries such as the Central African Republic may be of concern if diamonds are used to fund human rights abuses.

\section{ENTER TECHNOLOGY}

In addition to the problem of conflict diamonds, the diamond industry faces perhaps its greatest challenge in the form of disruptive technology. Disruptive innovation, a theory generally credited to Clay Christensen (Bower \& Christensen 1995; Christensen 1997; Christensen, Raynor \& McDonald, 2015) describes how new entrants can disrupt an established market using new technology, serving an overlooked segment of the market, or delivering more appropriate functionality. These small firms generally can disrupt a market and deliver a sought-after product often at a lower cost. The theory of disruptive innovation is not without its critics (King \& Batartogtokn, 2015; Sampere, Bienenstock \& Zuckerman, 2016), however, the theory seems to fit well with changes taking place in the diamond industry. Disruptive innovation, where new entrants provide products which are "good enough" and at a lower price seem to be a major threat to the long-standing diamond industry structure. This is especially true for the important millennial market which is more price conscious, less brand obsessed, and more concerned with social issues and transparency.

The hope of making diamonds has been around for many years. In the 1940s and 1950s the first manmade, or cultured diamonds were produced. The process was very expensive and the diamonds were of a lower quality, used mainly for industrial purposes. Recent advances in diamond manufacturing have produced man-made diamonds that are physically identical to natural diamonds and virtually indistinguishable from the natural stones. Using a plasma reactor, carbon is heated to extreme temperatures to create what are in fact real diamonds. Laboratory diamonds can be made to order in terms of size and color, and can be flawless.

A number of companies are now producing man-made diamonds including Pure Grown Diamonds of New York, IIa Technologies of Singapore, and Diamond Foundry of San Francisco which uses the tagline "Diamonds. Evolved." The Diamond Foundry is a particularly interesting diamond manufacturer in the fact that it was funded in part by Leonardo DiCaprio, one of the main actors in the film, Blood Diamonds. Man-made diamonds are produced by replicating the way natural diamonds are produced by the earth but done above ground. Intense heat and pressure are applied to carbon through a technically sophisticated process to grow the precious stones which are marketed not as cheaper alternatives but as "evolved" or more modern and socially responsible diamonds.

While the process of producing man-made diamonds is still expensive, diamonds can be made in laboratories and sold at prices about 35\% lower than natural diamonds. Man-made diamonds also provide the advantage of being conflict free and can be made in the desired size and color suitable to the buyer's 
tastes and budget. As the new entrants gain scale it is conceivable that the price of man-made diamonds could even become more price competitive.

\section{INDUSTRY AND MARKET CHANGES}

A major target market for man-made diamonds is the millennial generation. Millennials seem to be less concerned about the fact that the diamond is produced above ground and more concerned about its transparency in sourcing and price. This seems especially true of millennials in China and India. The Chinese millennials like the lower price and the Indian millennials like the ability to buy a larger and higher quality diamond at the same price as a natural diamond (Segran, 2017). China and India represent large and growing markets for diamond sellers. American consumers, currently the largest consumers of diamonds, can also be sold on the idea that the diamond is "Made in the USA" when purchased by the American diamond growers. Laboratory diamonds can also be sold on the basis of being more environmentally friendly. Instead of digging large open pits in the earth and using a lot of mining equipment and energy, lab grown stones leave a very small carbon footprint and do not destroy the landscape we typically see in diamond mining.

For many years De Beers was able to create artificial scarcity by restricting diamond sales. Diamonds were valued for their scarcity as well as their beauty. If diamonds can be mass produced in laboratories and prices fall they run the risk of losing some appeal. Diamonds represent what is referred to as a "Veblen good" meaning demand is driven by higher prices and status (The Economist, 2017). Lower prices may not increase demand and could in fact lower demand as the good becomes commonplace. Mass produced diamonds have the potential to completely disrupt the market.

In response to the many challenges the firm faces, De Beers started making a fundamental change in company strategy. The company shifted its focus from supply management and price control to a more demand-oriented strategy. It began to sell off its diamond stockpile and promote its image as a quality provider of diamonds. Instead of promoting the industry as a whole, as it has done for years with its successful "a diamond is forever" ad campaign, De Beers is seeking to differentiate itself from the competition and develop a strong brand loyalty. The company has established and expanded retail outlets, referred to as De Beers Diamond Jewelers where customers can buy branded De Beers diamonds. De Beers has created the "FOREVERMARK" which is available through authorized jewelers. The FOREVERMARK is an inscribed symbol and number placed on every diamond which De Beers sells. The FOREVERMARK mark indicates that the diamond is "beautiful, rare, and responsibly sourced" according to the company. On the bright side for De Beers and the natural diamond industry as a whole, with the large deposits of diamonds in the world potentially having already been discovered, and demand for diamonds is increasing in China, India, and the Middle East, the industry may be able to withstand the turbulence of laboratory created diamonds, especially if natural stones can be effectively marketed. According to the Bain \& Company Global Diamond Report (2016), millennials represent a key driver in the market. With nearly 900 million millennials in the United States, India, and China having a combined income of around $\$ 8$ trillion this market may determine the future of the diamond industry.

If man-made diamonds become the standard for the diamond industry there is also a question about the effect this structural shift in the industry will have on employment in diamond producing countries. Many of the world's natural diamonds come from some of the poorest countries on earth. Not just miners but polishers, cutters, middlemen, and others working in diamond producing countries and beyond will be affected. The global recession of 2007-2008 and the lack of sales showed the effect on diamond workers in terms of their socio-economic well-being in India (Sen, Solanki\&Kisan, 2013) and the effect could be

much greater not only for India but many parts of Africa. While Russia and Canada have become major sources of diamonds, most rough stones still come from the African continent (Figure 2). 
FIGURE 2

\section{GLOBAL DIAMOND PRODUCTION}

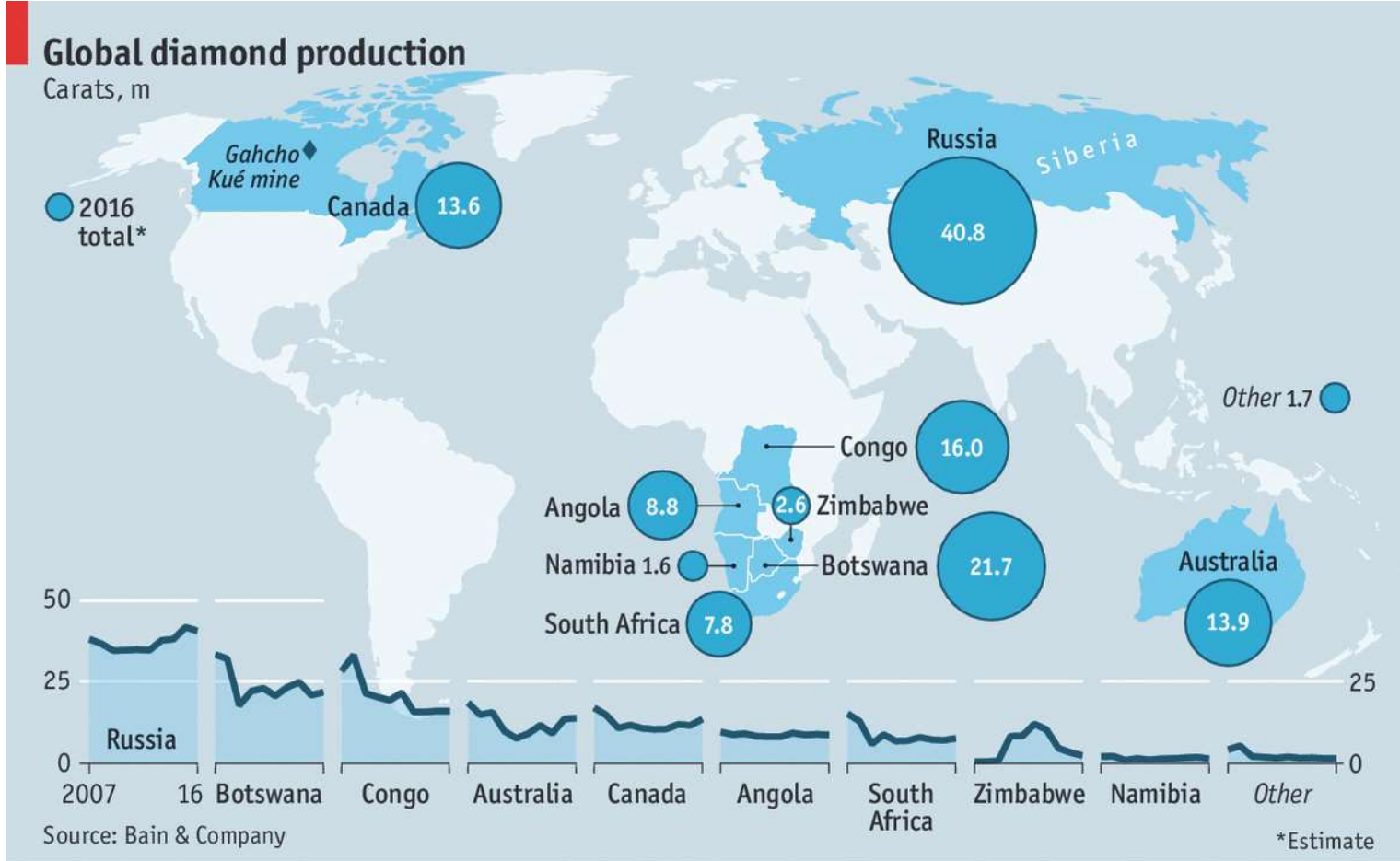

Economist.com

A diamond may be forever, but whether natural diamonds can continue to capture the vast component of the market remains in doubt. A number of questions remain. Will consumers embrace lab-grown diamonds as "real" diamonds, especially the millennials? What will happen to the structure of the industry and its workers? How will De Beers and others respond to this disruptive innovation, and will it be successful? 


\section{REFERENCES}

Bain \& Company. (2016). The Global Diamond Report 2016.

Bieri, F. (2010). From blood diamonds to the Kimberley process: How NGOs cleaned up the global diamond industry. New York: Routledge.

Bower, J. and C. Christensen. (1995). Disruptive technologies: Catching the wave. Harvard Business Review, 73 (1), 43-53.

Christensen, C. (1997). The innovator's dilemma: When new technologies cause great firms to fail. Boston: Harvard Business Press.

Christensen, C., M. Raynor, and R. McDonald. (2015). What is disruptive innovation? Harvard Business Review, 93 (12), 44-53.

Ewingmay, J. (2015). Changes are reshaping the world's diamond market. The New York Times, May 13. https://www.nytimes.com/2015/05/14/fashion/reshaping-the-worlds-diamond-market.html? $\mathrm{r}=0$.

Kimberley Process.(2017). https://www.kimberleyprocess.com/.Accessed on May 31, 2017.

King, A. and B. Baatarogtokh. (2015). How useful is the theory of disruptive innovation? MIT Sloan Management Review, 57 (1), 77-90.

Sampere, J, Bienenstock, M. and E. Zuckerman. (2016). Debating disruptive innovation. MIT Sloan Management Review, 57 (3), 26-30.

Sen, V., Solanki, M., and J. Kisan. (2013). Global recession and diamond industry workers: A socio economic perspective. Economic Literature, 11, 47-53.

Segran, E. (2017). This startup's plasma reactors create conflict-free diamonds for the millennial market. Fast Company, April 29. https://www.fastcompany.com/40402319/this-startups-plasma-reactorscreate-conflict-free-diamonds-for-the-millennial-marke.

The Economist. (2017). Production of the world's most valuable gem may be about to peak. February 25. http://www.economist.com/news/international/21717369-production-worlds-most-valuable-gemmay-be-about-peak-report-de-beerss. 